HOUSING POLICIES FOR DISABLED PEOPLE IN ENGLAND.

TRENDS IN ARCHITECTURE. THE INFLUENCE OF INTERNATIONAL ORGANISATIONS.

C Wycliffe Noble OBE FRIBA FRSA

The Royal Association for Disability and Rehabilitation, London, England. INTRODUCTION

My evaluation of the subject before us will undoubtedly be seen through the eyes of the town planner and architect for it is in this area of research and practice that $I$ have been associated at national and international level with The Royal Association for Disability and Rehabilitation, with Rehabilitation International and with International Organisation for Standardization.

It is timely I should speak here for it was at Nihon University some years ago that I first shared my hopes and aspirations with many Japanese Students.

As Consultant Architect to The Royal Association for Disability and Rhabilitation I have had a unique opportunity to represent a consumer organisation that seeks to interpret the diverse opinions of 3,000,000 disabled people in Britain .

It was founded in 1919 with representation at that time mainly in the area of orthopaedics but over many years this influence has expanded to be seen in development of facilities for disabled people in Education, Housing, Holidays, Employment, Access and Mobility, and in providing information. It is part funded by voluntary subscriptions and grants. One of its most important tasks is to service within our Parliament an All Party Disablement Group, which means that members of Parliament from differing political parties meet together with a common aim and purpose to discuss and achieve through the democratic process changes in attitude leading to changes in the law which are of benefit to disabled people.

RADAR was one of the pioneers in the integration theme and with The Royal Institute of British Architects have continuous1y supported me to enhance 
design standards and improve facilities for the handicapped.

For some time the planned environment and the responses of people to it have been the areas that sociologists have exhaustively researched, examined and pronounced upon and in many ways so far it has been the specialist who has influenced attitudes and shaped policy for disadvantaged people.

Today society is becoming increasingly aware of the status, worth and dignity of the individual and attention is being focused on the opinions of people who have to move around, live, are educated, find employment and pursue a leisure activity in hostile man-made or adapted environments.

The consumer is now a person we have to reckon with and it is as the result of action by user organisations who represent the disabled people who influence public opinion and Government that some progress has been made and it is the purpose of my presentation to use examples from a wide spectrum where there has been some achievement in the design of housing and public buildings. HOUSING FOR DISABLED PEOPLE

Provision in the UK of accommodation for disadvantaged people has been part of an English evolutionary process which goes back several centuries.

Much of this accommodation was provided by charities, trusts and foundations, who assumed a special responsibility for certain groups of the population and so emergec a variety of forms ranging frcm sanatoria, hostels, hospices and alms houses, which were often located in isolated and rural areas.

This resulted not only in a separation from those with special needs from the rest of the population, but gave rise as demands increased to a form of institutional and isolated provision.

\section{A HOUSING POLICY EMERGING}

The leap forward from the middle of this century from this situation was largely the result of pressure on Government Departments from users and organisations representing disabled people, where it was debated that peoples' 
needs and aspirations should be seen in alternative forms of housing set in the community rather than a continuation of building larger and more isolated forms of accommodation.

HOUSING DISABLED PEOPLE. THE ALTERNATIVES

Disabled people are not a single identifiable group of people with homogeneous housing requirements. They require appropriate housing in all parts of our, or any, country. They are found in all types of household groups: as children in their parental home, as single adults, as couples and with children. There are people with disabilities among those for whom 'special accommodation' is provided, such as housing for single young people, sheltered housing for elderly people or temporary emergency accommodation. A housing policy to meet the needs of people with disabilities must recognise this diversity and be both flexible and imaginative.

THE HOUSING FORMULAE

The housing form, rather than the institutional form, emerged as the result of changing attitudes and although some of the established charities continued to provide accommodation under post war social service legislation, the main thrust to provide housing for special needs was passed to housing departments of Local Government who had a duty to implement the housing policy approved by Parliament.

LOCAL GOVERNMENT PROVISION

Local Government therefore became the main providers of housing for disabled people and in 1974 the design requirements were set down, with its concept of 'Mobility' and 'Wheelchair Housing'. This provided a greater area of space accessible.

HOUSING ASSOCIATIONS. HOUSING ACT 1974

To provide a greater choice in housing where local initiative could be harnessed saw the rapid development of the Housing Association, a group which is non-profit making and obtains loans and grants from a central body known 
as The Housing Corporation to develop local schemes. There are now 2,600 Associations registered who are entrusted to build new housing and adapt older housing. About 1,000,000 people who would live in otherwise unsatisfactory conditions are provided with good quality homes.

It is claimed this is the most dynamic force in British Housing responsible for providing and managing over half million housing units.

\section{HOME OWNERSHIP}

The UK is of course increasingly becoming a nation of home owners.

DOE statistics indicate that in $196546 \%$ of stock was owner occupied and by 1985 it was $62 \%$ leaving only $27 \%$ housing in the control of Local Authorities with the balance of stock in the private rented sector.

PRIVATE SECTOR

New housing is also privided by private developers and contractors who voluntarily conform to standards of performance set down by The National House Building Council.

HOUSING ADAPTATIONS

Where Social Service Departments identify the need of an individual requiring an adaptation to the home in which they live, whether they are an owner or a tenant, a legal duty is placed on the authority to make arrangements for their provision. Grants are available for adaptations.

Housing benefit paid to disadvantaged people to assist them in the cost of their housing is a full part of the UK Social Security system. FAMILY SUPPORT

A call up system sometimes known as a family support scheme where care assistants provide services to disabled people, in their homes is of benefit to many people and enables families to remain together among their friends and neighbours. LOCAL AUTHORITIES. THE NEW ROLE

Together with this shift toward home ownership, Government is considering 
a new role for Local Authorities in which they should be seen "increasingly as enablers to ensure that everyone in their area is adequately housed". THE FUTURE

In the UK there is a variety of arrangements for housing disabled people prevailing and under review, and specific documents will be made available by postal enquiry through RADAR.

\section{THE PLANNED ENVIRONMENT}

From the examples we have considered we will be aware that housing is only one part of the range of buildings, milieu and infrastructure that people use, but for disabled people these opportunities are often denied and their hopes and aspirations for an integrated society are not attained.

People with impaired sight and hearing, people who cannot walk easily and people who have to use wheelchairs, often encountered difficulties because of the man-made handicapping features in the environment.

Those additional handicaps of architecture and attitude would dictate to disabled people which shop, library or post office they could use, which play, film or concert they could enjoy, which school or evening class they could attend, the job they could take and even whether they could work at all. They could dictate to disabled people when and how - and whether - they could do what able-bodied people could do.

Despite the advocacy for a demonstration of social responsibility and response from developers the educative process was slow and frustrating.

Although public awareness was effectively focused on this ussue in 1981 during The International Year of Disabled People, there was soon disenchantment in the following period in relation to progress. The implementation of an accessible environemt was still conditional in many countries upon the conviction and goodwill of developers, planners and architects, to ensure that the needs of disabled people were automatically taken into account. 


\section{CHANGING ATTITUDES}

Programmes to change peoples attitudes have in some industrialized societies required great effort and disabled people have become impatient at the effectiveness of the educative process. This has eventually required Governments to introduce laws governing the design of buildings to ensure that they meet the needs of people with disabilities.

\section{LEGISLATION}

By the way of example I use the UK model in which the planned environment of buildings and facilities within buildings are controlled by legislation and disabled people were involved in the consultation procedure before proposals were laid before Parliament. There are two pieces of legislation. The Town and Country Planning Acts and The Buildings(Disabled People) Regulation 1987. The former law requires the planner seeking a permission to use land for development to have his attention drawn to the needs of disabled people and following this when he constructs the building he will be required to incorporate into the design access, 1ifts, ramps and toilets. This legislation applies to new buildings.

\section{HERITAGE}

Like many countries with a heritage of architecture it is not always possible to achieve these arrangements in buildings of great historic interest.

Where this cannot be achieved by legislation then it is necessary in our Schools of Architecture to demonstrate what is possible with imagination, care and skill, and in the UK we have advocated the granting of awards for good building and the Royal Institute of British Architects and RADAR have held a quinquennial award scheme to encourage planners and designers. INTERNATIONAL CO-OPERATION

At international level we must always have regard for the difficulties encountered by developing countries who may not have the resources and 
technical skills to achieve what is being implemented elsewhere and we must respect the alternative technology that in some cases is the only option available to vast populations who live mainly in rural areas.

There is however, a danger when from outside a particular country investment and construction programmes are introduced which pay no regard to the mistakes that some developed countries have made and so a new generation of prestigious buildings, road networks, transport systems, are introduced into a new capital city of a developing country which ignore the future needs of the disabled population .

The International Commission on Technical Aids Building and Transportation has identified this issue and has published some guidelines which Government Departments in developing countries may follow as they plan for the future. INTERNATIONAL ORGANISATION FOR STANDARDIZATION

It is at this point that we consider the influence of harmonising design standards through the aegis of The International Organisation for Standardization.

ISO, whose HQ is in Geneva, in liaison with 400 other International Organisations, has published over 6,700 Standards, all of which have the same goal; better communication and better understanding between people of all nations.

It is a debatable point whether it is always possible at every level to attain standardisation in the planned environment where cultural, historical, climatic, economic, differences are manifest in differing parts of the world.

However, one must commend the pioneers of the International Organisation for Standardization who clearly see co-ordination and co-operation as one of great economic benefits for man as he seeks to trade in the markets of the world.

Already, we are aware of standardisation benefits where an electrical appliance, car component, or sports equipment, manufactured in one country can 
be used in another.

This must eventually have enormous advantages in the sphere of industrial design and in the low cost manufacture of technical aids for disabled people. But can the same principles be applied to architecture?

In architecture and planning however, unlike the development of a supersonic aircraft, there is no prototype to test; there is no trial run; there is no certificate of worthiness. In fact, in architecture all too often the people have to accept the proposition rather like marriage - "for better or for worse". Thus the population is provided with their new town centre or supermarket or road network whether they like it or not and whether or not it functions efficiently for all the people who wish to use the amenities.

In many cases therefore, the technology of shaping the environment around human behaviour fails because some minority groups - people with special needs are ignored, and it is on this issue that ISO has been taking the initiative. More specifically the policy of ISO has shifted in the area of design for disabled people due to the influence of Technical Committee 59 with its Working Group centred on The Swedish Institute for The Handicapped. Here it is emphasised that 'in all normal standard-making procedures, the requiremements of the disabled will now be considered not merely as a supplementary requirement of special provision, but as an integral part of standard-making procedure'.

The ISO Technical Report No DTR9527 based on this principle is progressing through its voting procedures and it will emerge this year as a valuable document on the international scene to assist those unfamiliar with this area of design.

CONCLUSION

In looking back on the achievements in the design of housing and the planned environment since I last visited Japan makes me believe that an old prosaic English statement is ture "in that it is better to travel hopefully than to arrive". 
I believe many disciplines represented here to-day are all contributing to that ever evolving goal in which able-bodied and disabled people will eventually equally share in the good things of life. Our journey is not yet complete.

May 1988 